\title{
Effects of Gomisin A on Liver Functions in Hepatotoxic Chemicals-Treated Rats?
}

\author{
Shinya MAEDA, Shigefumi TAKEDA, Yoshimasa MIYAMOTO, \\ Masaki ABURADA and Masatoshi HARADA* \\ Tsumura Research Institute for Pharmacology. 3586 Yoshiwara. Ami-cho. \\ Inashiki-gun, Ibaraki 300-11. Japan \\ *Faculty of Pharmaceutical Sciences. University of Chiba, \\ 1-33 Yayoi-cho. Chiba 260, Japan
}

Accepted Aprit 15, 1985

\begin{abstract}
The effects of gomisin A. which is a lignan component of schizandra fruits, on liver functions in various experimental liver injuries and on bile secretion in $\mathrm{CCl}_{4}$-induced liver injury were studied. Gomisin A weakly accelerated the disappearance of plasma ICG by itself at a high dose $(100 \mathrm{mg} / \mathrm{kg}$, i.p.). All of the hepatotoxic chemicals used in this study inhibited the excretion of ICG from plasma. Gomisin A showed a tendency to prevent the delays of the disappearance of plasma ICG induced by $\mathrm{CCl}_{4}$, d-galactosamine and orotic acid, but not that by ANIT. Bile flow and biliary outputs of total bile acids and electrolytes $\left(\mathrm{Na}^{+}, \mathrm{K}^{+}, \mathrm{Cl}^{-}\right.$and $\left.\mathrm{HCO}_{3}{ }^{-}\right)$ were decreased in $\mathrm{CCl}_{4}$-treated rats. Gomisin A maintained bile flow and biliary output of each electrolyte nearly to the level of the vehicle-treated group, but did not affect biliary output of total bile acids. These findings suggest that gomisin $\mathrm{A}$ possesses a liver function-facilitating property in normal and liver injured rats and that its preventive action on $\mathrm{CCl}_{4}$-induced cholestasis is due to maintaining the function of the bile acids-independent fraction.
\end{abstract}

We previously reported that gomisin $A$. schizandrin and their analogues, which are lignan components of schizandra fruits, showed preventive effects on some experimental liver injuries in serum-biochemical and histopathological examinations (1). The efficacy of gomisin A was the most prominent among the lignan components. The contents of Gomisin A in schizandra fruits is ca. 0.24 dry wt.\% (2).

In the present study, the effects of gomisin A on liver functions lowered by various hepatotoxic chemicals (carbon tetrachloride, d-galactosamine, $\alpha$-naphthylisothiocyanate and orotic acid) and on

† This work has been presented at the 63th Annual Meeting of the Japanease Pharmacological Society, Tokyo, 1980.

* Present address: The National Institute of Hygienic Sciences, 1-18-1 Kamiyoga. Setagayaku, Tokyo 158, Japan bile secretion in carbon tetrachloride-induced liver injury were investigated.

\section{Animals \\ Materials and Methods \\ Male Wistar strain rats weighing 200- $250 \mathrm{~g}$ were used. \\ Materials}

Gomisin A (Fig. 1) was isolated from schizandra fruits according to the method of Ikeya et al. (3). This compound was suspended in $2 \%(\mathrm{v} / \mathrm{v})$ Tween 80 -saline solution

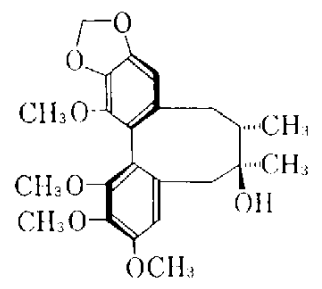

Fig. 1. Structure of gomisin A. 
just before the administration.

\section{Chemicals}

Carbon tetrachloride $\left(\mathrm{CCl}_{4}\right)$ was purchased from Wako Pure Chemical Ind. (Osaka, Japan), d-galactosamine hydrochloride from Sigma Chemical Co. (St. Louis, U.S.A.), $\alpha$ naphthylisothiocyanate (ANIT) from Eastman Kodak Co. (Rochester, U.S.A.), orotic acid from Tokyo Kasei Co. (Tokyo, Japan) and indocyanine green (ICG, Diagnogreen injection) from Daiichi Seiyaku Co. (Tokyo. Japan).

Methods

1. Effects of gomisin $A$ on liver functions (ICG-clearance) in various experimental liver injuries

1-a) Effects on plasma ICG in normal rats: Rats were anesthetized with intraperitoneal (i.p.) administration of pentobarbital- $\mathrm{Na}$ (50 $\mathrm{mg} / \mathrm{kg}$ ) $24 \mathrm{hr}$ after the i.p. administration of the material ( 50 and $100 \mathrm{mg} / \mathrm{kg}$ ) or vehicle. Two $\mathrm{ml} / \mathrm{kg}$ of $0.5 \%$ (W/V) ICG-distilled water solution was injected via the femoral vein, and about 120 , 2 of blood was collected from the tail vein using a hematocrit tube (Terumo. Tokyo, Japan) at 5, 10, 20, 30, 40, 50 and $60 \mathrm{~min}$ after the injection. Each blood sample was centrifuged at $10,000 \mathrm{rpm}$ for 5 min, using a centrifuge for hematocrit determination (Kubota/Model $\mathrm{KH}-120$ ). to obtain the plasma. Forty $\mu$ of plasma was added with $2 \mathrm{ml}$ of distilled water, and the absorbance at $805 \mathrm{~nm}$ was measured by using a spectrophotometer (Hitachi/Model 101). The amount of ICG was calculated from the previously constructed calibration curve.

1-b) Effects on plasma ICG in $\mathrm{CCl}_{4}$ treated rats: The material $(12.5-50 \mathrm{mg} / \mathrm{kg})$ was administered i.p. and $4 \mathrm{ml} / \mathrm{kg}$ of $50 \%$ (VN) $\mathrm{CCl}_{4}$-olive oil solution was orally (p.o.) given $30 \mathrm{~min}$ later. Twenty-four $\mathrm{hr}$ after the administration of $\mathrm{CCl}_{4}$, ICG was injected intravenously, and blood was periodically collected under anesthesia with pentobarbital-Na. The amount of plasma ICG was measured according to the procedure described in 1-a).

1-c) Effects on plasma ICG in $d$ galactosamine-treated rats: D-Galactosamine (400 $\mathrm{mg} / \mathrm{kg})$ was injected i.p. and the material $(50 \mathrm{mg} / \mathrm{kg}$ ) was also given i.p. $2 \mathrm{hr}$ later. The measurement of the amount of plasma ICG was performed with the same procedure as 1-a) $24 \mathrm{hr}$ after the administration of $d$-galactosamine.

1-d) Effects on plasma ICG in ANITtreated rats: Three $\mathrm{ml} / \mathrm{kg}$ of $1.5 \%$ (W/V) ANIT-olve oil solution was given p.o. daily for 4 days. The material ( $50 \mathrm{mg} / \mathrm{kg}$ ) was injected i.p. $30 \mathrm{~min}$ before every administration of ANIT. The amount of plasma ICG was measured using the same procedure as 1-a) $24 \mathrm{hr}$ after the last administration of ANIT.

1-e) Effects on plasma ICG in orotic acid-treated rats: Two \% (WN) orotic acidcontaining food (Oriental Kobo Co., Japan) was given for 12 days. The material was administered by adding it to the orotic acidmixed food at the rate of $50 \mathrm{mg}$ per $100 \mathrm{~g}$. The measurement of the amount of plasma ICG was performed $24 \mathrm{hr}$ after the last administration.

2. Effects of gomisin $A$ on bile secretion in $\mathrm{CCl}_{4}$-treated rats

The material $(50 \mathrm{mg} / \mathrm{kg}$ ) was administered i.p. and $4 \mathrm{ml} / \mathrm{kg}$ of $50 \%(\mathrm{~V} / \mathrm{N}) \mathrm{CCl}_{4}$-olive oil solution was given p.o. $30 \mathrm{~min}$ later. Rats were laparotomized under anesthesia with pentobarbital- $\mathrm{Na} 24 \mathrm{hr}$ after the administration of $\mathrm{CCl}_{4}$. A polyethylene tube (PE-10) was inserted into the common bile duct to drain bite off freely, and after $10 \mathrm{~min}$, the bile was collected for $60 \mathrm{~min}$ to measure the volume. Biliary concentration of total bile acids was measured using Sterognost- $3 \alpha$ (Daiichi Chemical Pharmaceutical Co.. Tokyo, Japan) and that of electrolytes ( $\mathrm{Na}^{+}$, $\mathrm{K}^{+}, \mathrm{Cl}$ and $\mathrm{HCO}_{3}{ }^{-}$) using Stat/lon II (Technicon Instruments Co., New York. U.S.A.).

\section{Statistical analysis}

The values were expressed as the mean \pm S.E. Statistical analysis was carried out using Student's $t$-test between the hepatotoxic chemical-treated group and the gomisin $A$ and hepatotoxic chemical-treated group.

\section{Results}

1. Effects of gomisin $A$ on liver functions (ICG-clearance) in various experimental liver injuries: a) Gomisin A slightly accelerated the disappearance of plasma ICG in normal rats 
$24 \mathrm{hr}$ after the administration of $100 \mathrm{mg} / \mathrm{kg}$. The excretion of ICG from plasma. This was i.p., but not at $50 \mathrm{mg} / \mathrm{kg}$, i.p. (Fig. 2). dose-dependently prevented by the pre-

b) $\mathrm{CCl}_{4}(2 \mathrm{ml} / \mathrm{kg}$, p.o. $)$ markedly inhibited treatment with gomisin $A(12.5-50 \mathrm{mg} / \mathrm{kg}$.

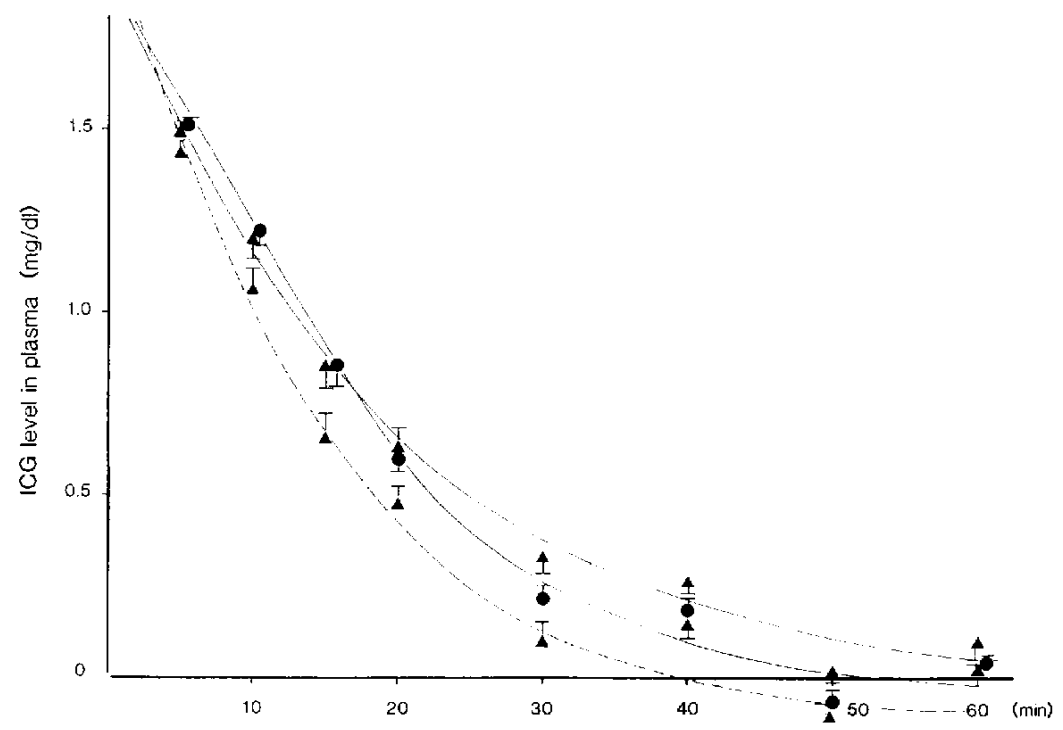

Fig. 2. Effects of gomisin A on disappearance of $I C G$ from blood in normal rats. - - - Vehicletreated group ( $\mathrm{n=8}$ ), $\mathbf{- \mathbf { A }}-$ : Gomisin A $(50 \mathrm{mg} / \mathrm{kg}$. i.p.)-treated group ( $\mathrm{n}=9), \cdots \mathbf{A} \cdots$ : Gomisin A $(100 \mathrm{mg} / \mathrm{kg}$, i.p.)-treated group $(n=9)$. Data are expressed as the mean \pm S.E.

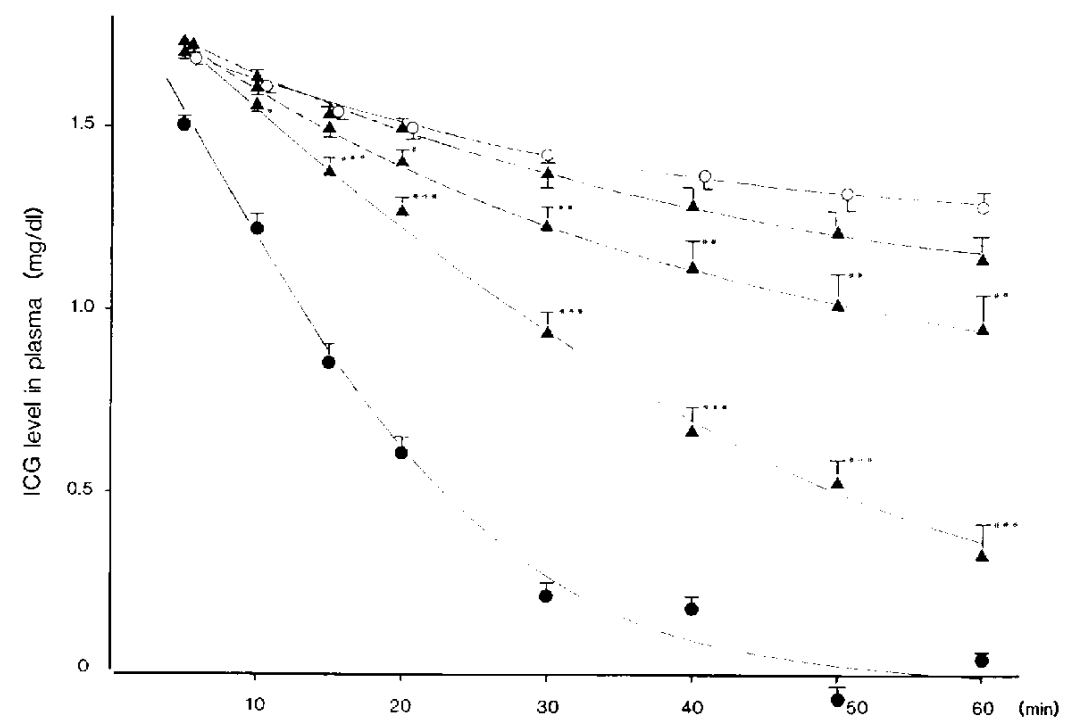

Fig. 3. Effects of gomisin $A$ on disappearance of $I C G$ from blood in $\mathrm{CCl}_{4}$-treated rats. $-\mathrm{O}-$ : $\mathrm{CCl}_{4}$ $\left(2 \mathrm{ml} / \mathrm{kg}\right.$, p.o.) -treated group $(\mathrm{n}=11),---\mathbf{\Delta}---$ : Gomisin $\mathrm{A}\left(12.5 \mathrm{mg} / \mathrm{kg}\right.$. i.p.) and $\mathrm{CCl}_{4}$-treated group $(n=10)$. - - $-\cdots$ : Gomisin A $\left(25 \mathrm{mg} / \mathrm{kg}\right.$. i.p.) and $\mathrm{CCl}_{4}$-treated group $(n=9),-\mathbf{A}-$ : Gomisin A $(50$ $\mathrm{mg} / \mathrm{kg}$, i.p.) and $\mathrm{CCl}_{4}$-treated group $(n=8),-\mathbf{-}-$ Vehicle-treated group $(n=8)$. Data are expressed as the mean \pm S.E. *.** and **: Statistically significant difference from the $\mathrm{CCl}_{4}$-treated group at $P<0.05, P<0.01$ and $P<0.001$, respectively. 
i.p.) (Fig. 3).

c) Gomisin A (50 mg/ $\mathrm{kg}$, i.p.) showed a tendency to prevent the delay of the disappearance of plasma ICG which was caused by $400 \mathrm{mg} / \mathrm{kg}$, i.p. of d-galactosamine (Fig. 4).

d) The repeated administration of ANIT ( $45 \mathrm{mg} / \mathrm{kg}$, p.o., daily for 4 days) delayed the

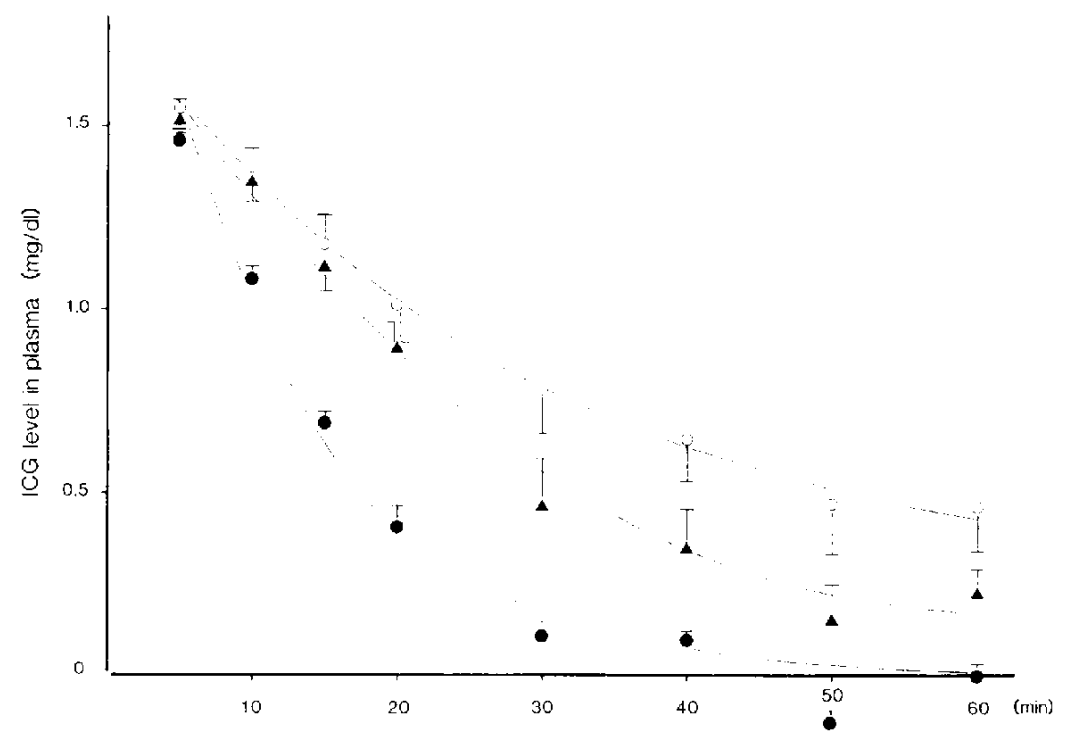

Fig. 4. Effects of gomisin A on disappearance of ICG from blood in d-galactosamine-treated rats. -O-: d-Galactosamine (400 mg/kg, i.p.)-treated group ( $n=11),-\mathbf{A}-\mathrm{d}$-Galactosamine and gomisin A $(50 \mathrm{mg} / \mathrm{kg}$. i.p.)-treated group $(n=9)$, - - Vehicle-treated group $(n=8)$. Data are expressed as the mean $\pm S$.E.

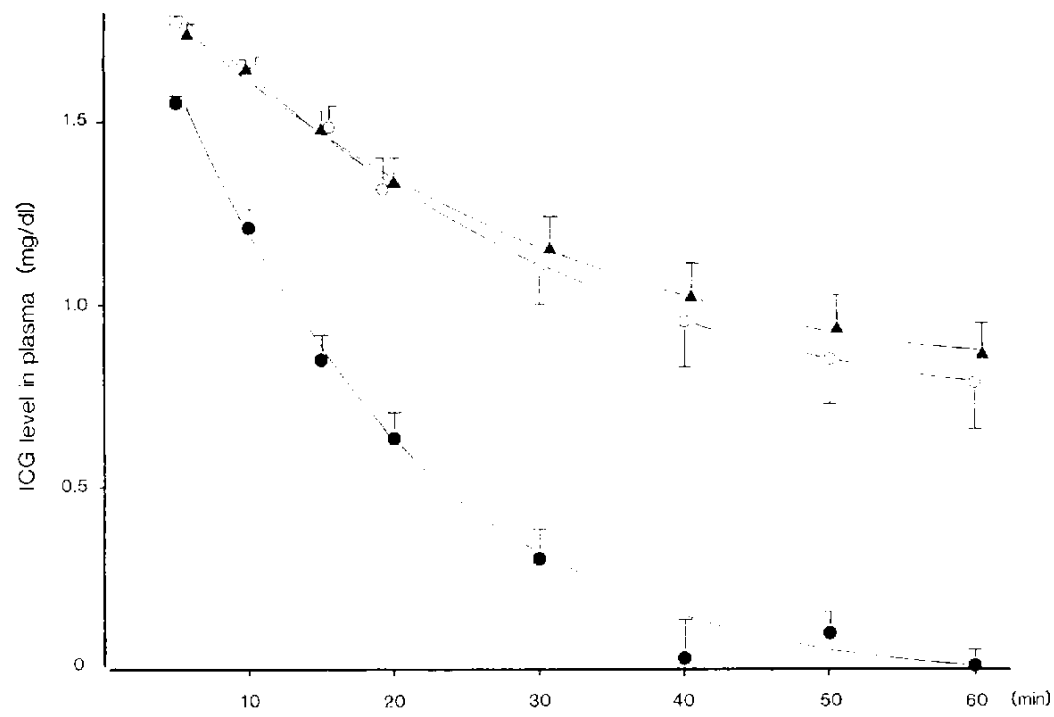

Fig. 5. Effects of gomisin A on disappearance of 1 CG from blood in ANIT-treated rats. -O-: ANIT $(45 \mathrm{mg} / \mathrm{kg}$, p.o.. daily for 4 days)-treated group $(n=13)$, - $\mathbf{A}-$ : Gomisin A $(50 \mathrm{mg} / \mathrm{kg}$, i.p., daily for 4 days) and ANIT-treated group $(n-14),-O-$ Vehicle-treated group $(n=11)$. Data are expressed as the mean \pm S.E. 


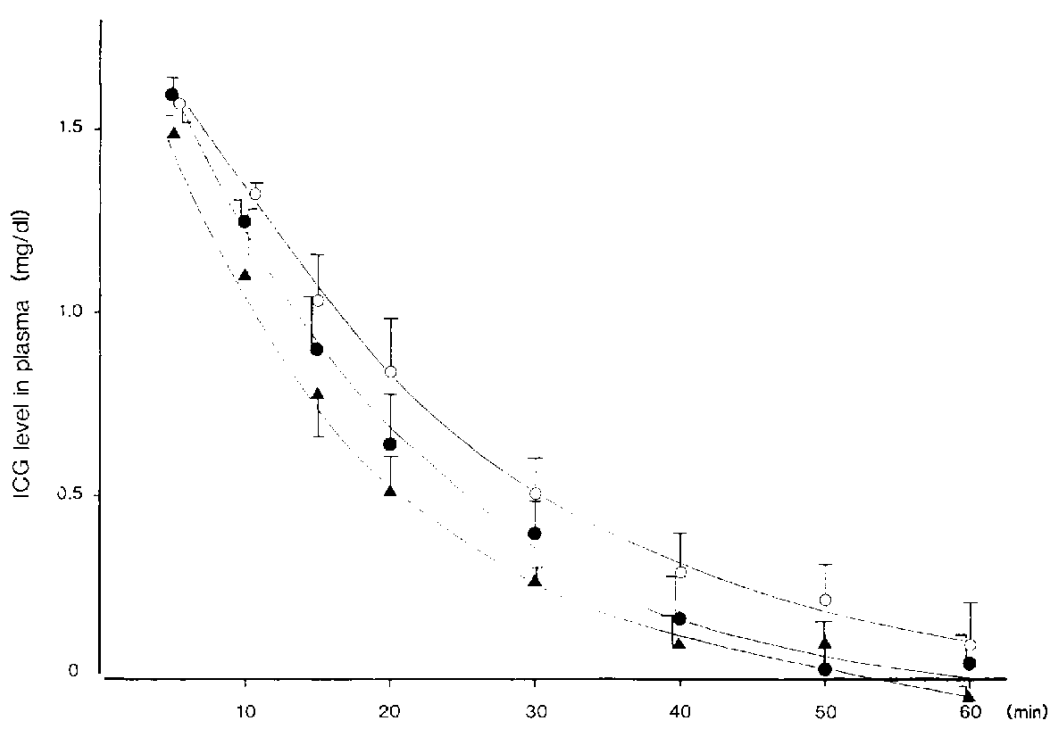

Fig. 6. Effects of gomisin A on disappearance of $1 \mathrm{CG}$ from blood in orotic acid-treated rats. -O$2 \%$ Orotic acid-mixed food (for 12 days)-treated group $(n=6)$, -- $\mathbf{A}-$ : Gomisin $A$ and orotic acidmixed food-treated group $(n=5)$. - - - Normal food-treated group $(n=5)$. Data are expressed as the mean $\pm S$.E.

disappearance of plasma ICG. Gomisin A $(50 \mathrm{mg} / \mathrm{kg}$. i.p., daily for 4 days) showed little influence on the ANIT-induced change (Fig. 5).

e) A tendency to inhibit the excretion of ICG was observed in rats fed the orotic acidcontaining food. The ICG level in plasma was maintained nearly to that of the normal food-treated group by the combined administration of gomisin A with orotic acid (Fig. 6).

2. Effects of gomisin $A$ on bile secretion in $\mathrm{CCl}_{4}$-treated rats: Bile flow and biliary outputs of total bile acids and electrolytes $\left(\mathrm{Na}^{+}, \mathrm{K}^{+}, \mathrm{Cl}^{-}\right.$and $\mathrm{HCO}_{3}^{-}$) were decreased by the administration of $\mathrm{CCl}_{4}(2 \mathrm{ml} / \mathrm{kg}$, p.o. $)$. Bile flow and biliary output of each of the electrolytes in the gomisin A (50 mg/ $\mathrm{kg}$, i.p.) pretreated group showed values near to those in the vehicle-treated group, but the decrease of biliary output of total bile acids in $\mathrm{CCl}_{4}$-treated rats was not affected by gomisin A (Tables 1 and 2).

\section{Discussion}

The effects of gomisin A. which is a lignan component of schizandra fruits, on liver functions in experimental liver injuries induced by $\mathrm{CCl}_{4}$, d-galactosamine, ANIT and orotic acid were studied using the ICGclearance test. Also, its effect on bile secretion in $\mathrm{CCl}_{4}$-induced liver injury was examined using bile flow and biliary total bile acids and electrolytes $\left(\mathrm{Na}^{+}, \mathrm{K}^{+}, \mathrm{Cl}^{-}\right.$and $\mathrm{HCO}_{3}{ }^{-}$) as parameters.

LD50 values of gomisin $A$ in mice are $390 \mathrm{mg} / \mathrm{kg}$, i.p., $500 \mathrm{mg} / \mathrm{kg}$. s.c. and 777 $\mathrm{mg} / \mathrm{kg}$, p.o., as reported in our previous paper (4).

Dyes such as ICG are actively taken up into the hepatocytes through the cell membranes from blood. This uptake mechanism is considered to be carrier-mediated (5). Therefore, the disappearance rate of ICG from blood indicates the condition of a liver function. Gomisin A slightly accelerated the disappearance of plasma ICG by itself at a high dose $(100 \mathrm{mg} / \mathrm{kg}$. i.p.). This fact indicates that gomisin A possesses a liver functionfacilitating property. Each of the hepatotoxic chemicals used in this study depressed a liver function. $\mathrm{CCl}_{4}$, d-galactosamine and ANIT markedly inhibited the excretion of ICG from plasma. Orotic acid also showed a similar effect, but it was less pronounced as compared with those of the aforementioned three chemicals. $\mathrm{CCl}_{4}$ is considered to 

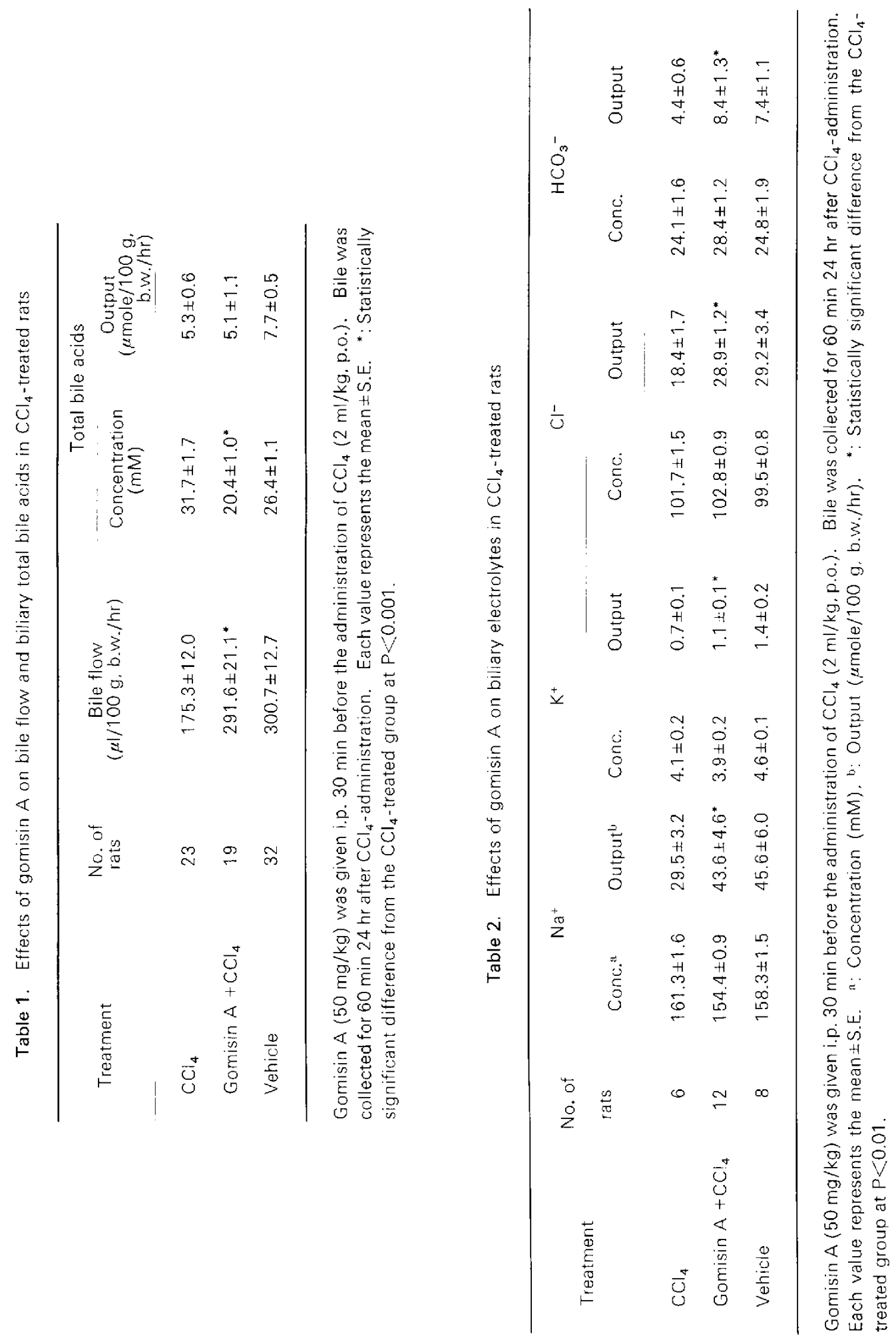
induce a hepatocellular injury and a fatty degeneration by $\mathrm{CCl}_{3}$ free radical $(6,7)$; $d$ galactosamine causes a necrosis by the depletion of hepatic uridine store (8): ANIT causes a intrahepatic cholestasis by cholangitis (9): and orotic acid causes a fatty liver by the repression in transport of lipoproteins (10). Gomisin A showed a tendency to prevent the delays of the disappearance of plasma ICG which was caused by $\mathrm{CCl}_{4}$, dgalactosamine and orotic acid, but not that by ANIT. These findings suggest that gomisin A may protect a lowered liver function in parenchymal injuries, and such preventive effects of gomisin A on hepatotoxicities may have partly resulted from the protective action on the hepatocytes (1).

A cholestasis and the decreases in biliary output of total bile acids and electrolytes $\mathrm{Na}^{+}$, $\mathrm{K}^{+} \cdot \mathrm{Cl}^{-}$and $\mathrm{HCO}_{3}{ }^{-}$) were observed after the administration of $\mathrm{CCl}_{4}$. The pretreatment with gomisin $\mathrm{A}$ in $\mathrm{CCl}_{4}$-treated rats maintained bile flow and biliary output of each electrolyte nearly to the levels of the vehicle-treated group, but did not affect biliary output of total bile acids. Besides, gomisin A has no choleretic action in normal rats (4). Canalicular bile consists of at least two fractions, one of which (bile acids-dependent fraction) is related to a secretion of bile acids. The other fraction (bile acids-independent fraction) is considered to result from active transport of $\mathrm{Na}^{+}$into the bile canaliculi (1113). From our results, it is probable that gomisin A has little effect on the biliary output of total bile acids and that its preventive effect on cholestasis is due to maintaining the function of the bile acidsindependent fraction.

Acknowledgements: We thank Dr. H. Taguchi and Dr. Y. Ikeya of Tsumura Laboratory for advice and assistance on the preparation of gomisin $\mathrm{A}$.

\section{References}

1 Maeda, S., Sudo, K., Miyamoto, Y., Takeda, S., Shinbo, M., Aburada, M., Ikeya, Y., Taguchi, H. and Harada, M.: Pharmacological studies on schizandra fruits. II. Effects of constituents of schizandra fruits on drug induced hepatic damage in rats. Yakugaku Zasshi 102, 579-588 (1982) (Abs. in English)

2 Nakajima, K., Taguchi, H., Ikeya, Y., Endo, T. and Yoshioka, 1:: The constituents of Schizandra chinensis Baill. XIII. Quantitative analysis of lignans in the fruits of Schizandra chinensis Baill. by high performance liquid chromatography. Yakugaku Zasshi 103, 743-749 (1983) (Abs. in English)

3 Ikeya, Y., Taguchi, H., Yoshioka, I. and Kobayashi $H .:$ The constituents of schizandra chinensis Baill. I. Isolation and structure determination of five lignans, gomisin $A, B, C, F$ and $G$, and the absolute structure of schizandrin. Chem. Pharm. Bull. (Tokyo) 27, 1383-1394 (1979)

4 Maeda, S., Sudo, K., Aburada, M., Ikeya, Y., Taguchi, H., Yoshioka, I. and Harada, M.: Pharmacological studies on schizandra fruits. I. General pharmacological effects of gomisin A. and schizandrin. Yakugaku Zasshi 101, 10301041 (1981) (Abs. in English)

5 Fox, I.J. and Wood, E.H.: Indocyanin green: Physical and physiologic properties. Proceedings of the Staff Meeting of Mayo Clinic 35, 732-744 (1960)

6 Recknagel, R.O.: Carbon tetrachloride hepatotoxicity. Pharmacol. Rev. 19, 145-208 (1967)

7 Robinson, D.S. and Seakins, A.: Observations relating to the mechanism of action of carbon tetrachloride. Biochem. J. 82, 9 (1962)

8 Decker, K. and Keppler, D.: Galactosamine induced liver injury. In Progress in Liver Disease, Edited by Popper, H. and Schaffner, F., Vol. IV. p. 183-199, Grune \& Stratton, New York (1972)

9 Fukumoto, Y., Okita, K., Kodama, T., Noda, K., Harada, T., Mizuta, M. and Takemoto, T.: Studies of $\alpha$-naphthylisothiocyanate-induced hepatic disturbance. Hepatogastroenterology 27, 457-464 (1980)

10 Lombardi, B.: Considerations on the pathogenesis of fatty liver. Lab. Invest. 15, 1-20 (1966)

11 Boyer, J.L.: Canalicular bile formation in the isolated perfused rat liver. Am. J. Physiol. 221, 1156-1163 (1971)

12 Forker, E.L.: Mechanisms of hepatic bile formation. Annu. Rev. Physiol. 39, 323-437 (1977)

13 Erlinger, S., Dhumeaux, D., Berthelot, P. and Dumont, M.: Effects of inhibitors of sodium transport on bile formation in the rébbit. Am. J. Physiol. 219, 416-422 (1970) 